\title{
PENGARUH BPJS TERHADAP MINAT MASYARAKAT DALAM UPAYA PENINGKATAN KESEHATAN DI RSUD DOLOKSANGGUL KECAMATAN DOLOKSANGGUL KABUPATEN HUMBANG HASUNDUTAN TAHUN 2014
}

\author{
Adelima C. R. Simamora, Doni Simatupang, Agustina Boru Gultom \\ Jurusan Keperawatan Poltekkes Kemenkes Medan
}

\begin{abstract}
Abstrak
Badan Penyelenggaran Jaminan Sosial (BPJS) merupakan badan hukum yang dibentuk untuk menyelenggarakan program jaminan sosial. Sehingga dengan adanya jaminan sosial ini resiko keuangan yang dihadapi oleh seseorang diambil alih oleh lembaga yang menyelenggarakan jaminan sosial. Tujuan penelitian ini adalah untuk mengetahui pengaruh BPJS terhadap minat masyarakat dalam upaya peningkatan kesehatan. Jenis penelitian yang digunakan dalam penelitian ini bersifat Deskriptif analitikdengan pendekatan Retrospektif. Instrumen penelitian menggunakan kuesioner dan melakukan wawancara. Menggunakan analisis bivariat dengan uji chi-square. Jumlah sampel 84 orang responden. Hasil penelitian menunjukkan mayoritas menerima BPJS dengan minat baik sebanyak 35 responden (83,3\%), berpendidikan SMA 22 responden $(75,9 \%)$, bekerja sebagai petani 23 responden $(59,0 \%)$, sumber informasi dari petugas kesehatan 40 responden $(83,3 \%)$.. Selain itu mayoritas yang berminat baik mengatakan program BPJS akan meningkatkan kesehatan masyarakat sebanyak 38 responden $(90,5 \%)$, berpendidikan SMA 26 responden $(89,7 \%)$, bekerja sebagai petani 30 responden $(76,9 \%)$, sumber informasi dari petugas kesehatan 42 responden $(87,5 \%)$. Berdasarkan hasil penelitian dapatdisarankan hendaknya masyarakat lebih meningkatkan kesehatan dengan ikut serta dalam memanfaatkan program BPJS.
\end{abstract}

Kata kunci : BPJS, Minat, Kesehatan Masyarakat

\section{PENDAHULUAN}

Menurut WHO (World Health Organization) kesehatan adalah suatu keadaan fisik, mental, dan sosial kesejahteraan dan bukan hanya ketiadaan penyakit atau kelemahan. Untuk itu diselenggarakan pembangunan kesehatan secara menyeluruh dan berkesinambungan, dengan tujuan guna meningkatkan kesadaran, kemauan dan kemampuan hidup sehat bagi setiap orang agar terwujud derajat kesehatan masyarakat yang setinggitingginya.

Pembangunan kesehatan pada saat ini masih dihadapkan pada permasalahan belum optimalnya akses, keterjangkauan, dan mutu pelayanan kesehatan antara lain disebabkan oleh sarana pelayanan kesehatan Rumah Sakit, Puskesmas, dan jaringannya belum sepenuhnya dijangkau oleh masyarakat, terutama bagi penduduk miskin terkait dengan adanya permasalahan dalam hal biaya dan juga jarak pelayanan kesehatan yang bisa dijangkau. (BPJS Kesehatan, diakses 18/03/2014).

Ada hal yang berubah pada awal Januari 2014, terutama di sektor kesehatan. Sesuai UU No 24 tahun 2011 tentang Badan Penyelenggara Jaminan Sosial (BPJS) mengamanatkan PT Askes (Persero) menjadi BPJS Kesehatan pada tanggal 1 Januari 2014. (BPJS, diakses 18/03/2014).
Seluruh penduduk Indonesia wajib menjadi peserta jaminan kesehatan yang dikelola oleh BPJS, termasuk orang asing yang telah bekerja paling singkat 6 bulan di Indonesia dan telah membayar iuran. Program ini diharapkan dapat menaungi seluruh masyarakat. Dengan demikian, masyarakat dapat dilindungi dengan asuransi kesehatan.

Badan Penyelenggara Jaminan Sosial (BPJS) merupakan Badan Usaha Milik Negara yang ditugaskan khusus oleh pemerintah untuk menyelenggarakan jaminan pemeliharaan kesehatan bagi seluruh rakyat Indonesia, terutama untuk Pegawai Negeri Sipil, Penerima Pensiun PNS dan TNI/POLRI, Veteran, perintis kemerdekaan beserta keluarganya dan Badan Usaha lainnya ataupun rakyat biasa.

Badan Penyelenggara Jaminan Sosial (BPJS) Kesehatan dan BPJS Ketenagakerjaan dahulu bernama Jamsostek merupakan program pemerintah dalam kesatuan Jaminan Kesehatan Nasional (JKN) yang diresmikan pada tanggal 31 Desember 2013. Untuk Badan Penyelenggara Jaminan Sosial (BPJS) Kesehatan mulai beroperasi sejak tanggal 1 Januari 2014, sedangkan Badan Penyelenggara Jaminan Sosial (BPJS) Ketenagakerjaan mulai beroperasi sejak 1 Juli 2015. 


\section{TINJAUAN TEORITIS}

\section{Pengertian}

Minat merupakan perhatian, kesukaan, ataupun kecenderungan hati. (Kamus Besar Bahasa Indonesia).

Minat adalah kecenderungan yang menetap/kesukaan terhadap suatu kegiatan melebihi kegiatan lainnya serta berfungsi untuk daya penggerak yang mengarahkan seseorang melakukan kegiatan tertentu yang spesifik

\section{Faktor-faktor yang mempengaruhi minat}

a. Pendidikan

Pendidikan adalah sebuah proses atau kegiatan pembelajaran untuk mengembangkan pembelajaran atau meningkatkan kemampuan tertentu sehingga sasaran pendidikan itu dapat berdiri sendiri. Pengubahan sikap dan tata laku seseorang atau kelompok dan juga usaha mendewasakan manusia melalui upaya pengajaran dan pelatihan. Demikian juga jika pendidikan SD, SMP, SMA, dan DIII/Sarjana hendak digabungkan kedalam satu variabel bernama tingkat pendidikan (Notoadmodjho, 2010).

b. Pekerjaan

Pekerjaan merupakan suatu kegiatan atau aktivitas seseorang untuk memperoleh penghasilan guna memenuhi kebutuhan hidup sehari-hari. Pekerja/karyawan adalah mereka yang bekerja pada orang lain atau institusi, kantor, perusahaan dengan menerima upah dan gaji baik berupa uang atau barang, sedangkan lapangan pekerjaan/jabatan adalah macam pekerjaan yang dilakukan atau ditugaskan pada seseorang (Notoatmodjho, 2010).

c. Sumber Informasi

Sumber informasi merupakan data yang diperoleh dalam suatu bentuk yang mempunyai arti bagi sipenerima dan mempunyai nilai nyata yang terasa bagi keputusan mendatang (Notoatmodjho, 2010).

\section{Badan Penyelenggara Jaminan Sosial (BPJS)}

Badan Penyelenggara Jaminan Sosial (BPJS) adalah badan hukum yang dibentuk untuk menyelenggarakan program jaminan sosial (UU No 24 tahun 2011).

Fungsi Badan Penyelenggara Jaminan Sosial (BPJS) UU BPJS (Badan penyelenggara Jaminan Sosial) menentukan bahwa BPJS Kesehatan berfungsi menyelenggarakan program jaminan kesehatan. Jaminan kesehatan menurut UU SJSN (Sistem Jaminan Sosial Nasional) diselenggarakan secara nasional berdasarkan prinsip asuransi sosial dan prinsip ekuitas, dengan tujuan menjamin agar peserta memperoleh manfaat pemeliharaan kesehatan dan perlindungan dalam memenuhi kebutuhan dasar kesehatan.

Tugas Badan Penyelenggara Jaminan Sosial (BPJS)

Dalam melaksanakan fungsi sebagaimana tersebut diatas Badan Penyelenggara Jaminan Sosial (BPJS) bertugas untuk:

1. Melakukan dan menerima pendaftaran peserta

2. Memungut dan mengumpulkan iuran dari peserta dan pemberi kerja

3. Menerima bantuan iuran dari pemerintah
4. Mengelola dana jaminan sosial untuk kepentingan peserta

5. Mengumpulkan dan mengelola data peserta program jaminan sosial

6. Membiayai pelayanan kesehatan sesuai dengan ketentuan program jaminan sosial

7. Memberikan informasi mengenai penyelenggaraan program jaminan sosial kepada peserta atau masyarakat

Wewenang Badan Penyelenggara Jaminan Sosial (BPJS)

Dalam melaksanakan tugasnya, Badan

Penyelenggara Jaminan Sosial (BPJS) berwenang untuk :

1. Menagih pembayaran iuran. Kewenangan menagih pembayaran iuran dalam arti meminta pembayaran dalam hal terjadi penunggakan, kemacetan, atau kekurangan pembayaran.

2. Menempatkan dana jaminan sosial untuk investasi jangka pendek dan jangka panjang dengan mempertimbangkan aspek likuiditas, solvabilitas, kehati-hatian, keamanan dana, dan hasil yang memadai.

3. Melakukan pengawasan dan pemeriksaan atas kepatuhan peserta dan pemberi kerja dalam memenuhi kewajiban sesuai dengan ketentuan peraturan perundang-undangan jaminan sosial nasional.

4. Membuat kesepakatan dengan fasilitas kesehatan mengenai besar pembayaran fasilitas kesehatan yang mengacu pada standar tarif yang ditetapkan oleh pemerintah.

5. Membuat atau menghentikan kontrak kerja dengan fasilitas kesehatan.

6. Mengenakan sanksi administratif kepada peserta atau pemberi kerja yang tidak memenuhi kewajibannya

7. Melaporkan pemberi kerja kepada instansi yang berwenang mengenai ketidakpatuhannya dalam membayar iuran atau dalam memenuhi kewajiban lain sesuai dengan ketentuan peraturan perundang-undangan.

8. Melakukan kerjasama dengan pihak lain dalam rangka penyelenggaraan program jaminan sosial.

\section{Hak dan Kewajiban Peserta}

a. Hak Peserta

1. Mendapatkan kartu peserta sebagai bukti sah untuk memperoleh pelayanan kesehatan

2. Memperoleh manfaat dan informasi tentang hak dan kewajiban serta prosedur pelayanan kesehatan sesuai dengan ketentuan yang berlaku

3. Mendapatkan pelayanan kesehatan pertama, yaitu Rawat Jalan Tingkat Pertama (RJTP) dan Rawat Inap Tingkat Pertama (RITP)

4. Mendapatkan pelayanan kesehatan rujukan tingkat lanjutan, yaitu Rawat Jalan Tingkat Lanjutan (RJTL) dan Rawat Inap Tingkat Lanjutan (RITL)

5. Mendapatkan pelayanan persalinan 
6. Mendapatkan pelayanan gawat darurat

7. Mendapatkan pelayanan ambulan bagi pasien rujukan dengan kondisi tertentu antar fasilitas kesehatan

8. Menyampaikan keluhan/pengaduan, kritik dan saran secara lisan atau tertulis ke kantor BPJS Kesehatan

b. Kewajiban Peserta

1. Mendaftarkan dirinya sebagi peserta serta membayar iuran yang besarnya sesuai dengan ketentuan yang berlaku.

2. Melaporkan perubahan data peserta, baik karena pernikahan, perceraian, kematian, kelahiran, pindah alamat atau pindah fasilitas kesehatan tingkat I.

3. Menjaga kartu peserta agar tidak rusak, hilang atau dimanfaatkan oleh orang yang tidak berhak.

4. Mentaati semua ketentuan dan tata cara pelayanan kesehatan.

\section{Iuran Wajib Peserta BPJS}

Besar iuran untuk peserta pekerja bukan penerima upah dan peserta bukan pekerja berdasarkan nominal bukan presentase yaitu untuk rawat inap perorang perbulan yaitu :

a. Kelas 1 sebesar Rp 59.500,-

b. Kelas 2 sebesar Rp 42.500,-

c. Kelas 3 sebesar Rp 25.500,-

\section{METODE PENELITIAN}

Jenis penelitian ini adalah Deskriptif Analitik dengan pendekatan Retrospektif. Deskriptif analitik adalah penelitian yang mendeskripsikan suatu objek yang diteliti melalui sampel atau data yang terkumpul dan membuat kesimpulan yang berlaku secara umum, sedangkan pendekatan retrospektif adalah penelitian yang bersifat melihat ke belakang (Notoatmodjo, 2010). Bertujuan untuk mengetahui "Pengaruh BPJS terhadap minat masyarakat dalam upaya peningkatan kesehatan di RSUD Doloksanggul Kecamatan Doloksanggul Kabupaten Humbang Hasundutan Tahun 2014".

\section{HASIL DAN PEMBAHASAN}

Penelitian ini dilakukan di RSUD Doloksanggul Kecamatan Doloksanggul Kabupaten Humbang Hasundutan. Fasilitas yang dimiliki oleh RSUD Doloksanggul adalah tempat tidur 75 unit, UGD, ICU, Rontgen, Laboratorium, UTDRS, Kamar bedah dan unit penunjang lainnya.

Adapun hasil penelitian yang dilakukan berjudul "Pengaruh BPJS Terhadap Minat Masyarakat Dalam Upaya Peningkatan Kesehatan di RSUD Doloksanggul Kecamatan Doloksanggul Kabupaten Humbang Hasundutan Tahun 2014" adalah sebagai berikut

\section{Analisa Univariat}

Analisa univariat dilakukan untuk menggambarkan penyajian data dari beberapa variabel dalam bentuk tabel distribusi frekuensi meliputi distribusi frekuensi berdasarkan minat, pendidikan, pekerjaan, dan sumber informasi tentang program BPJS dalam upaya peningkatan kesehatan masyarakat di RSUD Doloksanggul Kecamatan Doloksanggul Kabupaten Humbang Hasundutan tahun 2014.

Tabel 1 Distribusi Frekuensi Responden Berdasarkan Minat, Pendidikan, Pekerjaan, dan Sumber Informasi tentang BPJS Dalam Upaya Peningkatan Kesehatan di RSUD Doloksanggul Kecamatan Doloksanggul Kabupaten Humbang Hasundutan tahun 2014.

\begin{tabular}{|c|c|c|c|}
\hline No & Variabel & Jumlah & Persentase (\%) \\
\hline \multirow[t]{5}{*}{$\overline{1}$} & Minat & & \\
\hline & Baik & 43 & 51,2 \\
\hline & Cukup & 27 & 32,1 \\
\hline & Kurang & 14 & 16,7 \\
\hline & Total & 84 & 100 \\
\hline \multirow[t]{6}{*}{$\overline{2}$} & Pendidikan & & \\
\hline & $\mathrm{SD}$ & 14 & 16,7 \\
\hline & SMP & 24 & 28,6 \\
\hline & SMA & 29 & 34,5 \\
\hline & PT & 17 & 20,2 \\
\hline & Total & 84 & 100 \\
\hline \multirow[t]{6}{*}{$\overline{3}$} & Pekerjaan & & \\
\hline & Petani & 39 & 46,4 \\
\hline & IRT & 8 & 9,5 \\
\hline & PNS & 14 & 16,7 \\
\hline & Wiraswasta & 23 & 27,4 \\
\hline & Total & 84 & 100 \\
\hline \multirow[t]{6}{*}{$\overline{4}$} & Sumber Informasi & & \\
\hline & Petugas Kesehatan & 48 & 57,1 \\
\hline & Media Elektronik & 13 & 15,5 \\
\hline & Media Cetak & 6 & 7,1 \\
\hline & Lingkungan & 17 & 20,2 \\
\hline & Total & 84 & 100 \\
\hline \multirow[t]{4}{*}{$\overline{5}$} & BPJS & & \\
\hline & Menerima & 60 & 71,4 \\
\hline & Menolak & 24 & 28,6 \\
\hline & Total & 84 & 100 \\
\hline \multirow[t]{4}{*}{6} & Kesehatan Masyarakat & & \\
\hline & Meningkat & 71 & 84,5 \\
\hline & Tidak meningkat & 13 & 15,5 \\
\hline & Total & 84 & 100 \\
\hline
\end{tabular}

Berdasarkan tabel 1 dapat dilihat bahwa dari 84 responden mayoritas responden memiliki minat yang baik terhadap program BPJS sebanyak 43 responden $(51,2 \%)$ dan minoritas memiliki minat yang kurang sebanyak 14 responden $(16,7 \%)$.

Analisa Bivariat

Tabel 2. Distribusi Frekuensi Pengaruh BPJS Terhadap Minat Masyarakat Dalam Upaya Peningkatan Kesehatan di RSUD Doloksanggul Kecamatan Doloksanggul Kabupaten Humbang Hasundutan Tahun 2014

\begin{tabular}{lcccccccc}
\hline No. Minat & \multicolumn{4}{c}{ BPJS } & & df & $\mathbf{X}^{2}$ \\
& & Menerima & Menolak & \multicolumn{2}{c}{ Total } & & \\
\cline { 2 - 7 } & $\mathbf{n}$ & $\mathbf{\%}$ & $\mathbf{n}$ & $\mathbf{\%}$ & $\mathbf{N}$ & $\mathbf{\%}$ & \\
\hline 1. Baik & 35 & 83,3 & 7 & 16,7 & 42 & 100 & & \\
2. Cukup & 16 & 57,1 & 12 & 42,9 & 28 & 100 & 2 & 6,067 \\
3. Kurang & 9 & 64,3 & 5 & 35,7 & 14 & 100 & & \\
\hline \multicolumn{1}{c}{ TOTAL } & $\mathbf{6 0}$ & $\mathbf{7 1 , 4}$ & $\mathbf{2 4}$ & $\mathbf{2 8 , 6}$ & $\mathbf{8 4}$ & $\mathbf{1 0 0}$ & & \\
\hline
\end{tabular}


Berdasarkan tabel 2 diketahui bahwa dari 2 responden yang berminat baik mayoritas menerima BPJS sebanyak 35 responden $(83,3 \%)$, minoritas menolak BPJS sebanyak 7 responden $(16,7 \%)$.

Dari 28 responden yang berminat cukup mayoritas menerima BPJS sebanyak 16 responden $(57,1 \%)$, minoritas menolak BPJS sebanyak 12 responden $(42,9 \%)$. Dari 14 responden yang kurang berminat mayoritas menerima BPJS sebanyak 9 responden $(64,3 \%)$, minoritas menolak BPJS sebanyak 5 responden $(35,7 \%)$.

Tabel 3 Distribusi Frekuensi Pengaruh BPJS Terhadap Minat Masyarakat Dalam Upaya Peningkatan Kesehatan Berdasarkan Pendidikan di RSUD Doloksanggul Kecamatan Doloksanggul Kabupaten Humbang Hasundutan Tahun 2014

\begin{tabular}{|c|c|c|c|c|c|c|c|c|}
\hline \multirow[t]{3}{*}{ No. Pendidikan } & \multicolumn{6}{|c|}{ BPJS } & \multirow{3}{*}{\multicolumn{2}{|c|}{ df $X^{2}$}} \\
\hline & \multicolumn{2}{|c|}{ Menerima } & \multicolumn{2}{|c|}{ Menolak } & \multicolumn{2}{|c|}{ Total } & & \\
\hline & $\mathbf{n}$ & $\%$ & $\mathbf{n}$ & $\%$ & $\mathbf{N}$ & $\%$ & & \\
\hline 1. SD & 7 & 50,0 & 7 & 50,0 & 14 & 100 & & \\
\hline 2. SMP & 16 & 66,7 & 8 & 33,3 & 24 & 100 & 3 & 6,049 \\
\hline 3. SMA & 22 & 75,9 & 7 & 24,1 & 29 & 100 & & \\
\hline $4 \mathrm{PT}$ & 15 & 88,2 & 2 & 11,8 & 17 & 100 & & \\
\hline TOTAL & 60 & 71,4 & 24 & 28,6 & 84 & 100 & & \\
\hline
\end{tabular}

Berdasarkan tabel 3 diketahui bahwa dari 14 responden berpendidikan SD yang menerima BPJS sebanyak 7 responden (50\%), menolak sebanyak 7 responden (50\%). Dari 24 responden berpendidikan SMP mayoritas menerima BPJS sebanyak 16 responden $(66,7 \%)$, minoritas menolak sebanyak 8 responden (33,3\%). Dari 29 responden yang berpendidikan SMA mayoritas menerima BPJS sebanyak 22 responden (75,9\%), minoritas menolak sebanyak 7 responden $(24,1 \%)$. Dari 17 responden yang berpendidikan perguruan tinggi mayoritas menerima BPJS sebanyak 15 responden $(88,2 \%)$, minoritas menolak sebanyak 2 responden $(11,8 \%)$.

Tabel 4 Distribusi Frekuensi Pengaruh BPJS Terhadap Minat Masyarakat dalam Upaya Peningkatan Kesehatan Berdasarkan Pekerjaan di RSUD Doloksanggul Kecamatan Doloksanggul Kabupaten Humbang Hasundutan Tahun 2014

\begin{tabular}{|c|c|c|c|c|c|c|c|c|}
\hline \multirow[t]{3}{*}{ No. Pekerjaan } & \multicolumn{6}{|c|}{ BPJS } & \multirow{3}{*}{\multicolumn{2}{|c|}{ df $\mathbf{X}^{2}$}} \\
\hline & \multicolumn{2}{|c|}{ Menerima } & \multicolumn{2}{|c|}{ Menolak } & \multicolumn{2}{|c|}{ Total } & & \\
\hline & $\mathbf{n}$ & $\%$ & n & $\%$ & $\mathbf{N}$ & $\%$ & & \\
\hline 1. Petani & 23 & 59,0 & 16 & 41,0 & 39 & 100 & & \\
\hline 2. IRT & 7 & 87,5 & 1 & 12,5 & 8 & 100 & 3 & 9,616 \\
\hline 3. PNS & 14 & 100 & 0 & 0 & 14 & 100 & & \\
\hline 4 Wiraswasta & 16 & 69,6 & 7 & 30,4 & 23 & 100 & & \\
\hline TOTAL & 60 & 71,4 & 24 & 28,6 & 84 & 100 & & \\
\hline
\end{tabular}

Berdasarkan tabel 4 diketahui bahwa dari 39 responden yang bekerja sebagai petani mayoritas menerima BPJS sebanyak 23 responden $(59,0 \%)$ dan minoritas menolak BPJS sebanyak 16 responden $(41,0 \%)$. Dari 8 responden yang bekerja sebagai IRT mayoritas menerima BPJS sebanyak 7 responden $(87,5 \%)$ dan minoritas menolak BPJS sebanyak 1 responden $(12,5 \%)$.
Dari 14 responden yang bekerja sebagai PNS mayoritas menerima BPJS sebanyak 14 responden (100\%) dan minoritas menolak BPJS tidak ada. Dari 23 responden yang bekerja sebagai wiraswasta mayoritas menerima BPJS sebanyak 16 responden $(69,6 \%)$ dan minoritas menolak BPJS sebanyak 7 responden $(30,4 \%)$.

Hasil penelitian menunjukkan bahwa tidak ada pengaruh antara pekerjaan terhadap kesehatan masyarakat dengan program BPJS di RSUD Doloksanggul Kecamatan Doloksanggul Kabupaten Humbang Hasundutan tahun 2014.

Menurut asumsi peneliti, pekerjaan tidak terlalu berpengaruh terhadap kesehatan masyarakat, ini mungkin disebabkan oleh variabel lain dalam penelitian seperti pendidikan.

\section{SIMPULAN}

Setelah dilakukan penelitian dan pembahasan tentang pengaruh BPJS terhadap minat masyarakat dalam upaya peningkatan kesehatan di RSUD Doloksanggul Kecamatan Doloksanggul Kabupaten humbang Hasundutan tahun 2014, pada 84 responden maka diambil kesimpulan sebagai berikut :

1. Ada pengaruh BPJS terhadap minat masyarakat dalam upaya peningkatan kesehatan di RSUD Doloksanggul Kecamatan Doloksanggul Kabupaten Humbang Hasundutan tahun 2014

2. Tidak ada pengaruh BPJS terhadap minat masyarakat dalam upaya peningkatan kesehatan berdasarkan pendidikan di RSUD Doloksanggul Kecamatan Doloksanggul Kabupaten Humbang Hasundutan tahun 2014

3. Ada pengaruh BPJS terhadap minat masyarakat dalam upaya peningkatan kesehtaan berdasarkan pekerjaan di RSUD Doloksanggul Kecamatan Doloksanggul Kabupaten Humbang Hasundutan tahun 2014

4. Ada pengaruh BPJS terhadap minat masyarakat dalam upaya peningkatan kesehatan berdasarkan sumber informasi di RSUD Doloksanggul Kecamatan Doloksanggul Kabupaten Humbang Hasundutan tahun 2014

5. Tidak ada pengaruh kesehatan masyarakat terhadap minat masyarakat dalam upaya peningkatan kesehatan di RSUD Doloksanggul Kecamatan Doloksanggul Kabupaten Humbang Hasundutan tahun 2014

6. Ada pengaruh kesehatan masyarakat terhadap minat masyarakat dalam upaya peningkatan kesehtan berdasarkan pendidikan di RSUD Doloksanggul Kecamatan Doloksanggul Kabupaten Humbang Hasundutan tahun 2014

7. Tidak ada pengaruh kesehatan masyarakat terhadap minat masyarakat dalam upaya peningkatan kesehatan berdasarkan pekerjaan di RSUD Doloksanggul Kecamatan 
Doloksanggul Kabupaten Humbang Hasundutan tahun 2014

8. Tidak ada pengaruh kesehatan masyarakat terhadap minat masyarakat dalam upaya peningkatan kesehatan berdasarkan sumber informasi di RSUD Doloksanggul Kecamatan Doloksanggul Kabupaten Humbang Hasundutan tahun 2014

9. Ada pengaruh BPJS terhadap minat masyarakat berdasarkan peningkatan kesehatan masyarakat di RSUD Doloksanggul Kecamatan Doloksanggul kabupaten Humbang Hasundutan tahun 2014

\section{Saran}

Berdasarkan hasil penelitian, peneliti memberikan beberapa saran sebagai berikut :

1. Kepada petugas kesehatan yang bekerja di RSUD Doloksanggul Kecamatan Doloksanggul Kabupaten Humbang Hasundutan agar lebih meningkatkan pengetahuan pasien tentang program BPJS dan meningkatkan pelayanan kesehatan kepada masyarakat yang menggunakan BPJS.

2. Kepada responden agar lebih meningkatkan pengetahuan mengenai program BPJS dalam kesehatan.

3. Kepada peneliti selanjutnya agar meneliti dan mempertimbangkan faktor-faktor lain yang dapat mempengaruhi minat masyarakat terhadap BPJS dalam upaya peningkatan kesehatan.

\section{DAFTAR PUSTAKA}

Arikunto, Suharsimi. 2010. Prosedur Penelitian. Yogyakarta: Rineka Cipta

Fachmi idris. Sistem Rujukan Berjenjang. Download $15 / 03 / 2014$

Idris, Fachmi. 2013. Pelayanan Kesehatan. Jakarta: Badan Penyelenggara Jaminan Sosial

Idris, Fachmi. 2013. Panduan Layanan Bagi Peserta BPJS. Jakarta: Badan Penyelenggara Jaminan Sosial

Idris, Fachmi. 2013. Administrasi Klaim Fasilitas Kesehatan BPJS Kesehatan. Jakarta: Badan Penyelenggara Jaminan Sosial

Kementerian koordinator bidang kesejahteraan rakyat. 2014. http://www.menkokesra.go.id/ada-pihak-taksetuju-bpjs

Notoatmodjo, soekidjo. 2010. Metodologi Penelitian Kesehatan. Jakarta: PT Rineka Cipta

Prasetyawati, Arsita. 2011. Ilmu Kesehatan Masyarakat. Yogyakarta: Nuha Medika

Sembiring, Yustinus. 2013. Humbang Hasundutan dalam Angka. Doloksanggul: BPS Kabupaten Humbang Hasundutan

Simanjuntak, Budiman. 2013. Profil Kesehatan Humbang Hasundutan Tahun 2012. Doloksanggul: Dinas Kesehatan Humbang Hasundutan

Syafrudin. 2009. Ilmu Kesehatan masyarakat. Jakarta: Trans Info Media

Thabrany, Hasbullah 